\title{
Musculoskeletal Problems in Overweight and Obese Children
}

\author{
Marjolein Krul, $M D^{1}$ \\ Jobannes C. van der Wouden, $P b D^{1}$ \\ François G. Schellevis, $M D, P b D^{2}$ \\ Lisette W. A. van Suijlekom-Smit, \\ $\mathrm{PbD}^{3}$ \\ Bart W. Koes, $P b D^{1}$ \\ 'Department of General Practice, Erasmus \\ MC, University Medical Center Rotterdam, \\ Rotterdam, The Netherlands \\ ${ }^{2}$ Department of General Practice, EMGO \\ Institute, VU University Medical Centre, \\ Amsterdam, and NIVEL, Netherlands Insti- \\ tute for Health Services Research, Utrecht, \\ The Netherlands \\ ${ }^{3}$ Department of Pediatrics, Erasmus MC, \\ and Sophia Children's Hospital Rotterdam, \\ Rotterdam, The Netherlands
}

Conflicts of interest: none reported

\section{CORRESPONDING AUTHOR}

Marjolein Krul, MD

Department of General Practice

Room Ff304

Erasmus MC University Medical Center

Rotterdam

PO Box 2040

3000 CA Rotterdam

The Netherlands

m.krul@erasmusmc.nl

\begin{abstract}
PURPOSE The obesity epidemic in children is spreading at alarming rates. Because musculoskeletal problems can influence physical activity, we compared the frequency of musculoskeletal problems in overweight and obese children with that in normal-weight children.
\end{abstract}

METHODS We performed a cross-sectional database and face-to-face interview study that included 2,459 children aged 2 to 17 years from Dutch family practices. We collected data on self-reported height and weight (body mass index), self-reported musculoskeletal problems in the 2 weeks before the interview, number of family physician consultations for musculoskeletal problems in 1 year, and age ( 2 age-groups were analyzed: 2 to 11 years and 12 to 17 years, because of the proxy interview in the youngest age-group). We calculated the odds ratio (OR) and 95\% confidence interval (Cl) for musculoskeletal problems in overweight and obese children, compared with normal-weight children.

RESULTS Overweight and obese children in both age-groups ( 2 to 11 years and 12 to 17 years) reported significantly more musculoskeletal problems ( $O R=1.86$; $95 \% \mathrm{Cl}, 1.18-2.93$; and $\mathrm{OR}=1.69 ; 95 \% \mathrm{Cl}, 1.08-2.65$, respectively) than normal-weight children. The total group of children who were overweight or obese reported more lower extremity problems than did the normal-weight children $(\mathrm{OR}=1.62 ; 95 \% \mathrm{Cl}, 1.09-2.41)$; furthermore, they reported more ankle and foot problems than children who were of normal weight $(\mathrm{OR}=1.92 ; 95 \% \mathrm{Cl}, 1.15$ 3.20). Overweight and obese children aged 12 to 17 years consulted their family physicians more often with lower extremity problems than did the normal-weight children $(\mathrm{OR}=1.92 ; 95 \% \mathrm{Cl}, 1.05-3.51)$.

CONCLUSION This study shows that overweight and obese children more frequently experience musculoskeletal problems than do normal-weight children.

Ann Fam Med 2009;7:352-356. doi:10.1370/afm.1005.

\section{INTRODUCTION}

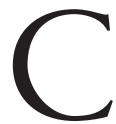

hildhood obesity is a serious health problem, and an obesity epidemic is spreading in alarming rates among children. ${ }^{1}$ Currently

about $16 \%$ of the children in Europe are overweight, and $8 \%$ are obese. $^{2}$ Obesity-associated problems and diseases decrease the quality of life and life span. Many studies have shown that overweight children are more likely to become overweight adults than their normal-weight peers. ${ }^{3-7}$ Furthermore, children may also be more vulnerable to specific obesityrelated health problems (such as hypertension, hepatic steatosis, hyperandrogenism, and pseudoacromegaly $)^{8}$ because their bodies are growing and developing.

Adult obesity has been associated with a higher prevalence of musculoskeletal disorders, primarily affecting the lower limbs, ${ }^{9-13}$ but comparative data in children are scarce. Some musculoskeletal disorders that are unique to childhood, such as slipped capital femoral epiphysis ${ }^{14}$ and tibia vara (Blount's disease), ${ }^{15}$ have retrospectively been associated with excess weight. Few studies have quantified the prevalence of musculoskeletal problems 
in overweight and obese children. ${ }^{16-19}$ Although these few studies imply that childhood obesity may predispose children to musculoskeletal problems, convincing empirical verification is currently lacking.

In our present research we use the results of a large survey in Dutch family practices performed in 2001 and aim to answer the following questions: (1) do overweight and obese children report more (lower extremity) musculoskeletal problems in daily life than their normal-weight peers; and (2) do overweight and obese children seek help for (lower extremity) musculoskeletal problems more often than their normal-weight peers?

\section{METHODS}

We analyzed data from the second Dutch national survey of family practice (NS2), which was carried out by the Netherlands Institute for Health Services Research (NIVEL) in 2001. The survey included a representative sample of the Dutch population; for further details see the article by Westert et al. ${ }^{20}$ This national survey consisted of morbidity registration by family physicians and face-to-face health interviews conducted in the Dutch language with a randomly selected sample of the listed patient population. Interview and morbidity data were linked and used for the present study.

\section{Interview}

An all-age, computer-generated sample of 150 registered patients per participating full-time family physician was invited to participate in an elaborate, face-to-face, multiple-choice health interview until the target number of 80 patients per physician had been reached. For nonresponders, attempts to contact (when possible), reason not to participate, sex, age, and zip code were documented. Trained interviewers performed the interviews, and the interviews were evenly distributed among 4 consecutive 3 -month periods to adjust for seasonal fluctuations. Items used for this study included age, self-reported height and weight, and self-reported musculoskeletal symptoms during the previous 2 weeks. If children were younger than 12 years, a proxy interview was carried out with a parent. To increase readability, the information provided by the parents is reported as if it were information provided by the children themselves.

\section{Morbidity Registration}

Morbidity data on the interviewed children were derived from the electronic medical records. The physicians registered all health problems reported during a consultation and coded the diagnosis using the International Classification of Primary Care (ICPC). The ICPC codes used to identify musculoskeletal problems are displayed in the Supplemental Appendix, which is available online at http://www.annfammed.org/ cgi/content/full/7/4/352/DC1). This survey was episode orientated, meaning that different consultations concerning the same health problem were clustered into 1 disease episode. Baseline characteristics (such as age and sex) were derived from patient records.

\section{Overweight and Obesity}

The body mass index (BMI) was used as a measure of overweight and obesity in the children ${ }^{21}$ and was based on self-reported weight and height. A standard developed for age-specific overweight and obesity BMI cutoff points in Dutch children was used to determine the presence of overweight and obesity in the study population. ${ }^{22}$ These cutoff points are almost identical to the recommended worldwide standard definition of overweight and obesity. ${ }^{23}$

\section{Study Population}

We analyzed interview data and corresponding physicians' morbidity registration data of the 2- to 17 year-old children. Only Dutch natives were included to reduce selection bias related to language and to enhance compatibility with BMI cutoff values that had been developed for native Dutch children. Children under the age of 2 years were excluded because obesity is not defined for this group. Among 2,719 eligible children, we analyzed data for 2,459 (90\%) for which we had height and weight information. A weighting factor was applied to compensate for differences between registration periods per practice. Children of normal weight and children with overweight and obesity contributed equal amounts of follow-up time.

\section{Analysis}

Using age- and sex-specific BMI cutoff value curves for Dutch native children, ${ }^{22}$ the children were divided into 3 groups: normal weight, overweight, and obese children. Because numbers were too small in the overweight and obese group to assess dose-effect relationships accurately, we chose to analyze overweight and obese children as 1 group. We have calculated odds ratios (ORs) and 95\% confidence intervals (CIs) comparing the overweight and obese children with the normal weight children. Odds ratios and confidence intervals not including 1 were considered significant. $t$ tests and $\chi^{2}$ analyses, as appropriate, were used to examine differences between these 2 groups. Significance was set at $P<.05$. We distinguished 2 age-groups, namely, children younger and older than 12 years of age, because of the proxy interview for children younger than 12 years. We calculated Mantel-Haenszel odds ratios to assess possible clustering 
of patients within physician practices. Analyses were conducted using Statistical Package for the Social Sciences, version 15.0 (SPSS Inc, Chicago, Illinois).

\section{Ethical Approval}

The study was carried out according to Dutch legislation on privacy. The Dutch Data Protection Authority approved the privacy regulation of the study. According to Dutch legislation, obtaining informed consent is not obligatory for observational studies.

\section{RESULTS}

\section{Participant Characteristics}

In total, 2,459 children were included in the analysis; $319(13.0 \%)$ were overweight or obese, 219 (8.9\%) and $100(4.1 \%)$, respectively. There was no significant difference between the children of normal weight and overweight and obese children in mean age or in the distribution of boys and girls within the age subgroups. Clustering within physician practices did not affect our outcome, as Mantel-Haenszel odds ratios were comparable to crude odds ratios.

\section{Self-Reported Musculoskeletal problems}

Self-reported musculoskeletal problems are shown in Table 1. Overweight and obese children in both age-groups ( 2 to 11 years and 12 to 17 years) reported significantly more musculoskeletal problems in daily life than did normal-weight children $(\mathrm{OR}=1.86 ; 95 \% \mathrm{CI}, 1.18-2.93$; and $\mathrm{OR}=1.6995 \% \mathrm{CI}, 1.08-2.65$, respectively). Children aged 2 to 11 years who were overweight or obese reported neck and back pain more often than did the normal-weight children in that age category $(\mathrm{OR}=2.60$; 95\% CI, 1.30-5.19). The total group of children who were overweight and obese reported more lower extremity problems than did the total normalweight group of children $(\mathrm{OR}=1.62$; 95\% CI, 1.09-2.41). We were able to split these lower extremity problems in a subgroup of hip and knee problems and a subgroup of ankle and foot problems. Ankle and foot problems were significantly more common in the total group and in the youngest age-group of overweight and obese children compared with these groups of normal-weight children $(\mathrm{OR}=1.92 ; 95 \% \mathrm{CI}, 1.15-3.20$; and $\mathrm{OR}=2.27 ; 95 \% \mathrm{CI}$, $1.15-4.47$, respectively). Rates of self-reported upper extremity problems did not differ between overweight and obese children and normal-weight children for either age subgroup.

\section{Musculoskeletal Problems Reported in Family Practice}

Episodes of health problems derived from the electronic medical record are displayed in Table 2. Among children aged 12 to 17 years, overweight and obese children consulted their family physicians more frequently with lower extremity problems $(\mathrm{OR}=1.92$; 95\% CI, 1.05-3.51). Regarding upper extremity problems and neck and back problems, there was no difference in consultation rate between children who were not overweight and the overweight and obese children.

\section{Table 1. Self-Reported Musculoskeletal Problems in Normal-Weight and Overweight and Obese Children}

\begin{tabular}{|c|c|c|c|}
\hline $\begin{array}{l}\text { Area of } \\
\text { Complaint }\end{array}$ & $\begin{array}{l}\text { Normal-Weight } \\
\text { Children } \\
\%(n)^{\mathrm{a}}\end{array}$ & $\begin{array}{l}\text { Overweight and } \\
\text { Obese Children } \\
\%(n)^{b}\end{array}$ & OR (95\%Cl) \\
\hline \multicolumn{4}{|c|}{ All musculoskeletal } \\
\hline All ages & 17.7 (379) & $21.9(70)$ & $1.31(0.98-1.74)$ \\
\hline $2-11$ y & $6.6(90)$ & $11.5(27)$ & $1.86(1.18-2.93)^{c}$ \\
\hline $12-17$ y & 37.7 (289) & $50.6(43)$ & $1.69(1.08-2.65)^{c}$ \\
\hline \multicolumn{4}{|c|}{ Neck and back } \\
\hline All ages & $9.6(206)$ & $10.7(33)$ & $1.12(0.76-1.66)$ \\
\hline $2-11$ y & $2.0(28)$ & $5.1(12)$ & $2.60(1.30-5.19)^{c}$ \\
\hline $12-17$ y & $23.2(178)$ & $25.9(22)$ & $1.15(0.69-1.93)$ \\
\hline \multicolumn{4}{|c|}{ Upper extremity } \\
\hline All ages & $1.2(26)$ & $1.3(4)$ & $1.03(0.36-2.98)$ \\
\hline $2-11$ y & $0.4(5)$ & $0.0(0)$ & NA \\
\hline $12-17$ y & $2.7(21)$ & $4.7(4)$ & $1.75(0.59-5.23)$ \\
\hline \multicolumn{4}{|c|}{ Lower extremity } \\
\hline All ages & $6.9(147)$ & $10.7(33)$ & $1.62(1.09-2.41)^{c}$ \\
\hline $2-11$ y & $4.1(57)$ & $6.8(16)$ & $1.70(0.96-3.01)$ \\
\hline $12-17$ y & $12.4(90)$ & $20.0(17)$ & $1.77(0.99-3.14)$ \\
\hline \multicolumn{4}{|l|}{ Hip and knee } \\
\hline All ages & $3.5(75)$ & $4.1(13)$ & $1.17(0.64-2.13)$ \\
\hline $2-11$ y & $1.8(25)$ & $1.7(4)$ & $0.94(0.32-2.72)$ \\
\hline $12-17$ y & $6.5(50)$ & $10.5(9)$ & $1.70(0.80-3.58)$ \\
\hline \multicolumn{4}{|c|}{ Ankle and foot } \\
\hline All ages & $3.4(72)$ & $6.3(20)$ & $1.92(1.15-3.20)^{c}$ \\
\hline $2-11$ y & $2.4(32)$ & $5.1(12)$ & $2.27(1.15-4.47)^{c}$ \\
\hline $12-17$ y & $5.5(40)$ & $10.0(8)$ & $1.89(0.85-4.17)$ \\
\hline \multicolumn{4}{|c|}{$\begin{array}{l}\text { Note: Positive response to survey question: In the last } 2 \text { weeks did you experience any } x x x \text { problems? } \\
\text { Reference group }(O R=1.0) \text { for each row is normal-weight children. }\end{array}$} \\
\hline \multicolumn{4}{|c|}{$\mathrm{NA}=$ not available. } \\
\hline \multicolumn{4}{|c|}{$\begin{array}{l}{ }^{a} \text { Group total }=2,140 \text {; age-group } 2-11 \mathrm{y}, \mathrm{n}=1,374 \text {; age-group } 12-17 \mathrm{y}, \mathrm{n}=766 \text {. } \\
{ }^{\mathrm{b}} \text { Group total }=319 ; \text { age-group } 2-11 \mathrm{y}, \mathrm{n}=234 ; \text { age-group } 12-17 \mathrm{y}, \mathrm{n}=85 \text {. } \\
{ }^{\mathrm{C}} P<.05 .\end{array}$} \\
\hline
\end{tabular}


Table 2. Musculoskeletal Problems Reported to Family Physicians in Normal-Weight and Overweight and Obese Children

\begin{tabular}{|c|c|c|c|}
\hline $\begin{array}{l}\text { Area of } \\
\text { Complaint }\end{array}$ & $\begin{array}{c}\text { Normal-Weight } \\
\text { Children }^{\mathrm{a}} \\
\%(\mathrm{n})\end{array}$ & $\begin{array}{c}\text { Overweight and } \\
\text { Obese Children }{ }^{b} \\
\%(n)\end{array}$ & OR (95\%Cl) \\
\hline \multicolumn{4}{|c|}{ All musculoskeletal } \\
\hline All ages & $14.1(301)$ & $16.0(51)$ & $1.16(0.84-1.61)$ \\
\hline $2-11$ y & 9.5 (130) & $10.3(24)$ & $1.09(0.69-1.73)$ \\
\hline $12-17$ y & $22.3(171)$ & $31.8(27)$ & $1.62(1.00-2.64)$ \\
\hline \multicolumn{4}{|c|}{ Neck and back } \\
\hline All ages & $2.1(45)$ & $3.1(10)$ & $1.51(0.75-3.02)$ \\
\hline $2-11$ y & $1.1(15)$ & $1.3(3)$ & $1.18(0.34-4.10)$ \\
\hline $12-17$ y & $3.9(30)$ & $8.2(7)$ & $2.20(0.94-5.18)$ \\
\hline \multicolumn{4}{|c|}{ Upper extremity } \\
\hline All ages & $1.8(38)$ & $2.2(7)$ & $1.24(0.55-2.80)$ \\
\hline $2-11$ y & $1.3(18)$ & $1.3(3)$ & $0.98(0.29-3.35)$ \\
\hline $12-17$ y & $2.6(20)$ & $4.7(4)$ & $1.84(0.62-5.52)$ \\
\hline \multicolumn{4}{|c|}{ Lower extremity } \\
\hline All ages & $6.1(130)$ & $7.8(25)$ & $1.32(0.84-2.10)$ \\
\hline $2-11$ y & $3.9(53)$ & $4.3(10)$ & $1.11(0.56-2.22)$ \\
\hline $12-17$ y & $10.1(77)$ & $17.6(15)$ & $1.92(1.05-3.51)^{c}$ \\
\hline \multicolumn{4}{|c|}{$\begin{array}{l}\text { Note: Illness episodes during prior } 12 \text { months recorded in family physician's electronic medical record. } \\
\text { Reference group (OR 1.0) for each row is normal-weight children. }\end{array}$} \\
\hline \multicolumn{4}{|c|}{$\begin{array}{l}{ }^{\mathrm{a}} \text { Group total }=2,140 \text {; age-group } 2-11 \mathrm{y}, \mathrm{n}=1,374 \text {; age-group } 12-17 \mathrm{y}, \mathrm{n}=766 \text {. } \\
\mathrm{b} \text { Group total }=319 ; \text { age-group } 2-11 \mathrm{y}, \mathrm{n}=234 \text {; age-group } 12-17 \mathrm{y}, \mathrm{n}=85 \text {. } \\
{ }^{\mathrm{C}} \mathrm{P}<.05 \text {. }\end{array}$} \\
\hline
\end{tabular}

\section{DISCUSSION}

In this large study of children aged 2 to 17 years seen in Dutch general practice, we found overweight and obese children reported musculoskeletal problems and lower extremity problems more frequently in daily life than did their normal-weight peers. Overweight and obese children aged 12 to 17 years were also more frequently seen by their family physician for lower extremity problems than were their peers of normal weight.

Ankle and foot problems are significantly more common in overweight and obese children compared with normal weight children in our study. A number of studies have focused on the foot structure of overweight and obese children ${ }^{24-27}$ showing that these children have increased foot length and width and decreased navicular height, ${ }^{24}$ lower medial arch height, ${ }^{25,26}$ and higher plantar pressure ${ }^{27}$ compared with normal-weight children. It therefore seems reasonable to assume that these structural problems in the feet of the overweight and obese children are correlated with the reported ankle and foot problems. This assumption has been postulated before, ${ }^{27,28}$ but unfortunately none of the foregoing studies was designed in a way that such a theory could be verified. Although our study adds credibility, further investigation is necessary to confirm whether there is a causal relationship.

Although the absolute difference may not be large, de Sa Pinto et a $\mathrm{l}^{19}$ have also reported more back pain among their obese children aged 7 to 14 years. In accordance with the same report, we found no differences in the occurrence of upper extremity problems between overweight and obese and normalweight children.

Overweight and obese children experience musculoskeletal problems more often. The association between a low fitness level and excess body weight has been described. ${ }^{29,30}$ Normal-weight children with musculoskeletal problems are possibly less active and can therefore become overweight, and musculoskeletal problems can prevent overweight and obese patients from successfully using exercise to reduce body weight. We hypothesize that a vicious circle results wherein being overweight, musculoskeletal problems, and a low fitness level reinforce each other. It is therefore important to be aware of the higher occurrence of musculoskeletal problems in these children, to provide adequate management of their problems, and to give healthy life style advice proactively.

\section{Limitations}

We used self-reported weight and height to determine the BMI, which may have introduced misclassification. We believe, however, that possible misclassification is limited, because we used face-to-face interviews, which promote validity of answers. ${ }^{31}$ Furthermore, people will tend to underestimate weight and overestimate height, resulting in an underestimation of the number of overweight and obese children. It is, therefore, not likely that the possible misclassification will have affected the positive relation found in this study. Our findings are supported by those of Strauss, ${ }^{32}$ who compared self-reported with actual weight and height. The study showed small differences in weight, but it did not have an impact in the assessment of obesity-related morbidity.

Although there was a $35 \%$ nonresponse for the interview, we argue that selection bias was limited. Our participants were sampled independently of general practice consultation, and the children in our sample, compared with data from Statistics Netherlands, were representative (by sex, age, and region) of the Dutch childhood population. Although approximately $10 \%$ of data on height and/or weight was missing, we believe the missing data were random, because the health 
interview was elaborate and covered many more topics than obesity and musculoskeletal problems.

Our study shows that overweight and obese children more frequently report musculoskeletal problems in daily life than do normal-weight children. In addition to more self-reported musculoskeletal problems in overweight and obese children, we also found that overweight and obese children older than 12 years sought medical help more frequently for their lower extremity problems than did their normal-weight peers.

\section{To read or post commentaries in response to this article, see it} online at http://www.annfammed.org/cgi/content/full/7/4/352.

Key words: Children; obesity; overweight; musculoskeletal

Submitted August 19, 2008; submitted, revised, January 1, 2009; accepted January 30, 2009

Funding support: The Dutch ministry of Health, Welfare and Sports mainly funded the surveys directly or indirectly. In addition, the 'Stichting Centraal Fonds RVVZ' contributed financially to the second survey. The analysis reported in this paper was made possible through internal funding of the department of General Practice, Erasmus MC-University Medical Center Rotterdam

Acknowledgments: The authors thank all the family physicians and family practices involved in this study.

\section{References}

1. Ten things you need to know about obesity. Presented at WHO European Ministerial Conference on Counteracting Obesity; November 15-17, 2006; Istanbul, Turkey. http://www.euro.who.int/document/nut/obesityconf_10things_eng.pdf.

2. Internation Association for the Study of Obesity. International Obesity Taskforce. May 24, 2004. EU "childhood obesity out of control". http://www.iaso.org/popout.asp?linkto=http\%3A//www.iotf. org/media/lOTFmay28.pdf.

3. Guo SS, Wu W, Chumlea WC, Roche AF. Predicting overweight and obesity in adulthood from body mass index values in childhood and adolescence. Am J Clin Nutr. 2002;76(3):653-658.

4. Whitaker RC, Wright JA, Pepe MS, Seidel KD, Dietz WH. Predicting obesity in young adulthood from childhood and parental obesity. N Engl J Med. 1997;337(13):869-873.

5. Eriksson J, Forsén T, Osmond C, Barker D. Obesity from cradle to grave. Int J Obes. 2003;27(6):722-727.

6. Serdula MK, Ivery D, Coates RJ, Freedman DS, Williamson DF, Byers T. Do obese children become obese adults? A review of the literature. Prev Med. 1993;22(2):167-177.

7. Power C, Lake JK, Cole TJ. Measurement and long-term health risks of child and adolescent fatness. Int J Obes. 1997;21(7):507-526.

8. Gunturu SD, Ten S. Complications of obesity in childhood. Pediatr Ann. 2007;36(2):96-101.

9. Tsuritani I, Honda R, Noborisaka Y, Ishida M, Ishizaki M, Yamada Y. Impact of obesity on musculoskeletal pain and difficulty of daily movements in Japanese middle-aged women. Maturitas. 2002;42(1):23-30.

10. Kortt M, Baldry J. The association between musculoskeletal disorders and obesity. Aust Health Rev. 2002;25(6):207-214.

11. He XZ, Baker DW. Body mass index, physical activity, and the risk of decline in overall health and physical functioning in late middle age. Am J Public Health. 2004;94(9):1567-1573.
12. Fabris de Souza SA, Faintuch J, Valezi AC, et al. Postural changes in morbidly obese patients. Obes Surg. 2005;15(7):1013-1016.

13. Aro S, Leino P. Overweight and musculoskeletal morbidity: a tenyear follow-up. Int J Obes. 1985;9(4):267-275.

14. Loder RT, Aronson DD, Greenfield ML. The epidemiology of bilateral slipped capital femoral epiphysis. A study of children in Michigan. J Bone Joint Surg Am. 1993;75(8):1141-1147.

15. Dietz WH Jr, Gross WL, Kirkpatrick JA Jr. Blount disease (Tibia vara) another skeletal disorder associated with childhood obesity. J Pediatr. 1992;101(5)735-737.

16. Henderson RC. Tibia vara: a complication of adolescent obesity. J Pediatr. 1992;121(3):482-486.

17. Taylor ED, Theim KR, Mirch MC, et al. Orthopedic complications of overweight in children and adolescents. Pediatrics. 2006;117(6): 2167-2174.

18. Bazelmans C, Coppieters Y, Godin I, et al. Is obesity associated with injuries among young people? Eur J Epidemiol. 2004;19(11): 1037-1042.

19. de Sá Pinto AL, de Barros Holanda PM, Radu AS, Villares SMF, Lima FR. Musculoskeletal findings in obese children. J Paediatr Child Health. 2006;42(6):341-344.

20. Westert GP, Schellevis FG, de Bakker DH, Groenewegen PP, Bensing JM, van der Zee J. Monitoring health inequalities through general practice: the Second Dutch National Survey of General Practice. Eur J Public Health. 2005;15(1):59-65.

21. Pietrobelli A, Faith MS, Allison DB, Gallagher D, Chiumello G, Heymsfield SB. Body mass index as a measure of adiposity among children and adolescents: a validation study. J Pediatr. 1998;132(2):204-210.

22. Hirasing RA, Fredriks AM, van Buuren S, Verloove-Vanhorick SP, Wit JM. [Increased prevalence of overweight and obesity in Dutch children, and the detection of overweight and obesity using international criteria and new reference diagrams]. Ned Tijdschr Geneeskd. 2001;145(27):1303-1308.

23. Cole TJ, Bellizzi MC, Flegal KM, Dietz WH. Establishing a standard definition for child overweight and obesity worldwide: international survey. BMJ. 2000;320(7244):1240-1243.

24. Morrison SC, Durward BR, Watt GF, Donaldson MDC. Anthropometric foot structure of peripubescent children with excessive versus normal body mass: a cross-sectional study. J Am Podiatr Med Assoc. 2007;97(5):366-370.

25. Villaroya MA, Esquivel JM, Tomás C, Buenafé A, Moreno L. Foot structure in overweight and obese children. Int J Pediatr Obes. 2007;2(1):1-7.

26. Mickle KJ, Steele JR, Munro BJ. The feet of overweight and obese young children: are they flat or fat? Obesity (Silver Spring). 2006;14(11):1949-1953

27. Dowling AM, Steele JR, Baur LA. What are the effects of obesity in children on plantar pressure distributions? Int J Obes. 2004;28(11):1514-1519.

28. Wearing SC, Hennig EM, Byrne NM, Steele JR, Hills AP. Musculoskeletal disorders associated with obesity: a biomechanical perspective. Obes Rev. 2006;7(3):239-250.

29. Kim J, Must A, Fitzmaurice GM, et al. Relationship of physical fitness to prevalence and incidence of overweight among schoolchildren. Obes Res. 2005;13(7):1246-1254.

30. Minck MR, Ruiter LM, Van Mechelen W, Kemper HC, Twisk JW. Physical fitness, body fatness, and physical activity: The Amsterdam Growth and Health Study. Am J Hum Biol. 2000;12(5):593-599.

31. de Leeuw ED, van der Zouwen J. Data quality in telephone and face-to-face surveys; a comparative meta-analysis. In: Telephone Survey Methodology. New York, NY: Wiley; 1988:283-300.

32. Strauss RS. Comparison of measured and self-reported weight and height in a cross-sectional sample of young adolescents. Int J Obes Relat Metab Disord. 1999;23(8):904-908. 